OPEN ACCESS

Edited by:

Dora ll'Yasova,

Duke University, USA

Reviewed by:

Lokesh Tiwari

St. Stephens Hospital, India Isadore Leslie Rubin,

Morehouse School of Medicine, USA

${ }^{*}$ Correspondence:

Takeo Fujiwara

fujiwara-tk@ncchd.go.jp

Specialty section:

This article was submitted to Child Health and Human Development,

a section of the journal

Frontiers in Public Health

Received: 12 December 2015 Accepted: 29 February 2016

Published: 17 March 2016

Citation:

Fujiwara T, Shimazu A, Tokita M, Shimada K, Takahashi M, Watai I, Iwata N and Kawakami N (2016)

Association between Parental

Workaholism and Body Mass Index of Offspring: A Prospective Study among Japanese Dual Workers.

Front. Public Health 4:41. doi: 10.3389/fpubh.2016.00041

\section{Association between Parental Workaholism and Body Mass Index of Offspring: A Prospective Study among Japanese Dual Workers}

\author{
Takeo Fujiwara ${ }^{1 *}$, Akihito Shimazu ${ }^{2}$, Masahito Tokita ${ }^{2}, K_{\text {Koko Shimada }}{ }^{2}$, \\ Masaya Takahashi ${ }^{3}$, Izumi Watai ${ }^{4}$, Noboru Iwata ${ }^{5}$ and Norito Kawakami ${ }^{2}$
}

${ }^{1}$ Department of Social Medicine, National Research Institute for Child Health and Development, Tokyo, Japan, ${ }^{2}$ Department of Mental Health, The University of Tokyo Graduate School of Medicine, Tokyo, Japan, ${ }^{3}$ National Institute of Occupational Safety and Health, Kanagawa, Japan, ${ }^{4}$ Department of Nursing, Nagoya University, Aichi, Japan, ${ }^{5}$ Department of Psychology, Hiroshima International University, Hiroshima, Japan

The purpose of the study was to investigate the association between parental workaholism and child body mass index (BMI) among Japanese dual-income families. In 2011, 379 dual-income families from urban Tokyo with children aged 0-5 years were recruited for a baseline survey, and 160 (42.2\%) were followed up in 2012. Demographics, workaholism, work demands, work control, time spent with children, and parental and child weights and heights were assessed using a questionnaire. Structural equation modeling was performed to determine the association between maternal and paternal workaholism in 2011 and child BMI in 2012, considering the mediating effects of time spent with children. Paternal workaholism showed a direct significant positive association with child BMI after 1 year (standardized coefficient: 0.19; $p<0.001$ ), while maternal workaholism was not associated with child BMI. Both maternal and paternal time spent with children did not mediate the association. Paternal work demands showed a strong positive association with workaholism but paternal work control did not. Paternal, but not maternal, workaholism was associated with an increase in child BMl over 1 year. Interventions that target workaholism by reducing paternal work demands might be effective in preventing overweight in offspring.

Keywords: child obesity, child overweight, parenting, working environment, work-life balance

\section{INTRODUCTION}

Over the past three decades, childhood obesity has increased worldwide, including Japan $(1,2)$. Children who are obese or overweight are more likely to be obese or overweight in adulthood (3). Further, childhood obesity can lead to a wide range of diseases, including hypertension (4), dyslipidemia (5), type 2 diabetes mellitus (6), sleep apnea (7), renal dysfunction (8), and depression (9). As dietary and exercise habits are difficult to change in adulthood, early interventions for childhood obesity are important to prevent obesity later in life $(1,10)$.

Determinants of childhood obesity vary from genetic to non-genetic factors (10). Non-genetic factors include bottle feeding (11), a sedentary lifestyle and longer periods of watching television $(12,13)$, and poor eating habits, such as larger intakes of sugar-sweetened beverages (14) or fast 
food (15). Recent studies suggest that these non-genetic factors related to childhood obesity might be determined by family factors, such as maternal employment or longer maternal working hours in conjunction with a rise in dual-income families (16-20). Moreover, both maternal and paternal working styles, such as the type of work schedule, have been investigated as determinants of child obesity (21-23).

However, these previous studies did not reveal which component of parental working style is associated with child obesity. We hypothesized that parental workaholism, which is defined as "the tendency to work excessively hard and to be obsessed with work" (24), can explain the association between parental working style and child body mass index (BMI). Higher work demands could induce higher parental workaholism, which might reduce the length of time spent with children and/or reduce the quality of that time (19). Given that, previous studies have reported that parenting or parent-child interactions had effects on child BMI (25-27), and time spent with children, which is a proxy of parent-child interaction, could also be associated with child BMI. Few studies have empirically revealed the association between parental workaholism and child BMI that take into account the impact of work demands and control on the time spent with children.

Further, it is necessary to investigate this hypothesis among dual-income families because time spent by the mother and time spent by the father interact with each other (28). The impact of parental workaholism and the mediating effects of time spent with children on child obesity can be investigated better among dual-working families. Among child-rearing families in Japan, the percentage of dual-working families is gradually increasing, from $29.7 \%$ in 1985 to $44.3 \%$ in 2013 (29). Here, we aim to investigate the association between parental workaholism and child BMI among dual-working families in Tokyo, Japan, using a prospective cohort study design.

\section{MATERIALS AND METHODS}

\section{Sample}

This study is a part of the Tokyo Work-Family Interface Study (TWIN) II, a large cohort study that commenced in 2011. We invited participants of TWIN I (30), the study we initially started, to participate in the TWIN II survey ( $N=321$ families). Additionally, we also approached all day care centers $(N=22)$ in another ward, Meguro city, with the permission of Meguro's day care division. We sent our research plan and consent forms to the principals of all day care centers. All principals agreed to participate and sent the research plan and consent forms to parents. After checking the signed consent forms from those parents who agreed to participate, we directly sent out questionnaires to participating parents' addresses $(N=357$ families). Therefore, questionnaires were distributed to all parents ( $N=678$ families $)$ in 2011, and 413 families responded to the questionnaire (response rate: $60.9 \%$ ). Further, follow-up questionnaires were distributed in 2012, and 229 responses were received (follow-up rate: $55.4 \%$ ). Of these, valid responses on workaholism and both parental and child BMI were received from 125 families (54.6\%).

\section{Measures}

Workaholism was assessed in the baseline questionnaire during the fiscal year (FY) of 2011. The questionnaire was based on the Japanese version of the Dutch Workaholism Scale, which showed good reliability and validity (31). The scale consists of two subscales: working excessively and working compulsively. Both subscales comprised five items with a 4-point Likert scale ( 1 = "totally disagree" and $4=$ "totally agree").

In addition, work demands and work control were assessed using the Brief Job Stress Questionnaire (32). Both scales were composed of three items (e.g., for work demand, "I am asked to do an excessive amount of work" and for work control, "I have influence over the pace of my work"), with a 4-point Likert scale ( 1 = "disagree" and $4=$ "agree"). The sum of all item responses was used for analysis.

Time spent with children was assessed using the following question: "How long do you spend with your child per week?"; responses included units of hours per week. The response was used as a continuous variable. Parental and child weights and heights were assessed using a self-reported questionnaire (i.e., self-reported for parental weight and height and parent-reported for child weight and height). Previous studies among Japanese have proven the high accuracy of self-reported child weights and heights $(33,34)$, as well as that for adults (35). BMI (kilogram/ square meter) was calculated as weight (kilogram) over height squared (square meter). Child BMI was adjusted for age and sex, and BMI $z$-scores were calculated based on World Health Organization standards (36). Parental BMI was collected from the baseline questionnaire in FY 2011, and child BMI was collected both at baseline in FY 2011 and at follow-up in FY 2012. Other covariates, including parental characteristics, such as age, annual household income, occupation, and status of maternity or paternity leave, were collected for both mothers and fathers, and child's sex and age were also assessed at baseline in FY 2011.

\section{Analysis}

First, to confirm whether workaholism and work demands and control reflected parental occupation, the mean scores of each work-related scale were compared between occupations of mothers and fathers using analysis of variance. Second, structural equation modeling was used to determine the association between maternal and paternal workaholism in 2011 and child BMI in 2012, considering the mediating effects of parental BMI, time spent with children, and child BMI in 2011. Further, we incorporated the association of both work demands and control related to workaholism with time spent with children in the model. Stata SE 13 (StataCorp, College Station, TX, USA) was used for the analysis.

\section{RESULTS}

Table 1 shows the characteristics of the sample. Mean paternal and maternal ages were 39.6 (SD: 6.3) and 38.0 (SD: 4.5) years, respectively. Mean BMI for fathers was 23.2 (SD: 3.0) and 20.1 (SD: 2.1) for mothers, which is consistent with the average BMI for this age group in Japan (37). Annual household income was skewed to 
TABLE 1 | Characteristics of the sample $(N=125)$.

\begin{tabular}{|c|c|c|c|c|c|c|c|}
\hline & & & & Mean or $n$ & SD or $\%$ & Min. & Max. \\
\hline \multirow[t]{24}{*}{ Parents } & Age (years) & Father & & 39.6 & 6.3 & 28 & 62 \\
\hline & & Mother & & 38.0 & 4.5 & 27 & 47 \\
\hline & $\mathrm{BMI}\left(\mathrm{kg} / \mathrm{m}^{2}\right)$ & Father & & 23.2 & 3.0 & 18.6 & 33.9 \\
\hline & & Mother & & 20.1 & 2.1 & 15.4 & 27.5 \\
\hline & Time spent with the child (hours/week) & Father & & 31.1 & 21.9 & 0 & 100 \\
\hline & & Mother & & 53.4 & 25 & 8.5 & 140 \\
\hline & Annual household income (million yen) & Paternal response & $<5$ & 8 & 6.4 & & \\
\hline & & & $5-<10$ & 50 & 40 & & \\
\hline & & & $10-<15$ & 38 & 30.4 & & \\
\hline & & & $15+$ & 25 & 20 & & \\
\hline & & & No answer & 4 & 3.2 & & \\
\hline & & Maternal response & $<5$ & 20 & 16.0 & & \\
\hline & & & $5-<10$ & 48 & 38.4 & & \\
\hline & & & $10-<15$ & 35 & 28.0 & & \\
\hline & & & $15+$ & 18 & 14.4 & & \\
\hline & & & No answer & 4 & 3.2 & & \\
\hline & Occupation & Father & Non-manual & 66 & 52.8 & & \\
\hline & & & Manual & 51 & 40.8 & & \\
\hline & & & Paternity leave & 1 & 0.8 & & \\
\hline & & & Other & 7 & 5.6 & & \\
\hline & & Mother & Non-manual & 46 & 36.8 & & \\
\hline & & & Manual & 69 & 55.2 & & \\
\hline & & & Maternity leave & 9 & 7.2 & & \\
\hline & & & Other & 1 & 0.8 & & \\
\hline \multirow[t]{5}{*}{ Child } & Sex & Male & & 77 & 61.6 & & \\
\hline & & Female & & 48 & 38.4 & & \\
\hline & Age (months) & & & 44.4 & 21.4 & 2 & 95 \\
\hline & z-score of child BMI & FY 2011 & & 0.002 & 1.05 & -2.39 & 2.37 \\
\hline & & FY 2012 & & -0.095 & 1.19 & -4.21 & 2.46 \\
\hline
\end{tabular}

the right, i.e., the sample was relatively wealthy, with more than half reporting an annual income of more than 10 million yen (equivalent to USD 80,000 as of 2015), as reported by fathers. Interestingly, mothers reported a lower annual household income than fathers. The type of paternal occupation was distributed almost equally for non-manual (52.8\%) and manual (40.8\%) jobs, and only one participant was taking paternity leave at the time of the survey. For mothers, manual occupations were in the majority (55.2\%) and non-manual occupations accounted for $36.8 \%$, while $7.2 \%$ of participants were taking maternity leave at the time of the survey. Regarding children's characteristics, boys were dominant at $61.6 \%$, and child ages ranged between 2 and 95 months. Mean $z$-scores of child BMI for both FY 2011 and 2012 were 0.002 and -0.095 , respectively, suggesting that participating children were not skewed to either overweight or underweight.

Associations between occupation and workaholism, work demands, and work control for both fathers and mothers are shown in Table 2. Among fathers, occupation did not significantly differentiate the scores for workaholism, work demands, and work control (all $p>0.2$ ). However, among mothers, occupation differentiated the scores for workaholism and work demands (both $p<0.05$ ). More specifically, mothers on maternity leave showed a higher score of workaholism and work demands than mothers currently working in non-manual or manual occupations (both $p<0.05)$. Further, mothers with manual occupations had lower scores for work control $(p<0.05)$.

Figure 1 shows the structural equation model that estimates the causal path of workaholism and $z$-scores of child BMI 1 year after baseline. The hypothesized model showed acceptable goodness-of-fit indices: chi-square $=203.14(p<0.001)$, root mean square error of approximation (RMSEA) $=0.000,95 \%$ confidence interval $=0.000-0.052$, and comparative fit index $(\mathrm{CFI})=1.000$. As shown, paternal workaholism was directly associated with $z$-scores of child BMI 1 year after baseline (standard coefficient: $0.19, p<0.05$ ), that is, time spent with children or paternal BMI did not mediate the association. Paternal work demands were positively significantly associated with paternal workaholism (standard coefficient: $0.61, p<0.05$ ) while paternal work control was associated with time spent with children (standard coefficient: $0.28, p<0.05$ ), as expected. Interestingly, maternal workaholism was not associated with $z$-scores of child BMI 1 year after baseline, neither directly nor indirectly. That is, although maternal workaholism was inversely associated with maternal BMI (standard coefficient: $-0.19, p=0.061$ ) and time spent with children (standard coefficient: $-0.14, p=0.074$ ), these were not associated with $z$-scores of child BMI. Maternal work demands and control were both associated with maternal workaholism (standard coefficient: 0.45 and $-0.14, p<0.05$ and $p=0.078$, respectively). Further, time spent with children showed strong correlations for both mothers and fathers (standard coefficient: $0.25, p<0.05$ ).

\section{DISCUSSION}

To the best of our knowledge, this is the first study to report that paternal workaholism, but not maternal workaholism, was 
TABLE 2 | Work-related psychometric scales by occupation $(N=125)$.

\begin{tabular}{|c|c|c|c|c|c|c|c|}
\hline & & \multirow[t]{2}{*}{ Total } & \multicolumn{4}{|c|}{ Occupation } & \multirow{3}{*}{$p$} \\
\hline & & & $\begin{array}{l}\text { Non-manual ( } n=66 \\
\text { for father, } n=46 \\
\text { for mother) }\end{array}$ & $\begin{array}{l}\text { Manual ( } n=51 \\
\text { for father, } n=69 \\
\text { for mother) }\end{array}$ & $\begin{array}{c}\text { Paternity/maternity } \\
\text { leave ( } n=1 \text { for father } \\
\text { and } n=9 \text { for mother) }\end{array}$ & $\begin{array}{l}\text { Others ( } n=7 \text { for } \\
\text { father and } n=1 \\
\text { for mother) }\end{array}$ & \\
\hline & & \multicolumn{2}{|l|}{ Mean (SD) } & \multicolumn{2}{|c|}{ Mean (SD) } & & \\
\hline \multirow[t]{2}{*}{ Workaholism } & Father & $21.8(6.1)$ & $22.6(6.1)$ & 21.5 (5.9) & $21.0(\mathrm{NA})$ & $18.0(6.9)$ & 0.27 \\
\hline & Mother & $20.9(5.6)$ & $20.4(5.5)$ & $20.8(5.3)$ & $24.9(6.5)$ & $10.0(\mathrm{NA})$ & 0.03 \\
\hline \multirow[t]{2}{*}{ Work demands } & Father & $8.8(2.0)$ & $9.1(2.0)$ & $8.5(2.1)$ & 8.0 (NA) & $8.4(1.6)$ & 0.46 \\
\hline & Mother & $8.4(2.0)$ & $8.0(2.0)$ & $8.5(1.9)$ & $10.1(1.4)$ & $3.0(\mathrm{NA})$ & 0.0014 \\
\hline \multirow[t]{2}{*}{ Work control } & Father & $9.1(1.9)$ & $9.3(1.7)$ & $8.7(2.1)$ & $9.0(\mathrm{NA})$ & $9.7(2.0)$ & 0.36 \\
\hline & Mother & $8.24(2.0)$ & $8.7(1.8)$ & $7.8(2.0)$ & $8.9(2.4)$ & $11.0(\mathrm{NA})$ & 0.058 \\
\hline
\end{tabular}

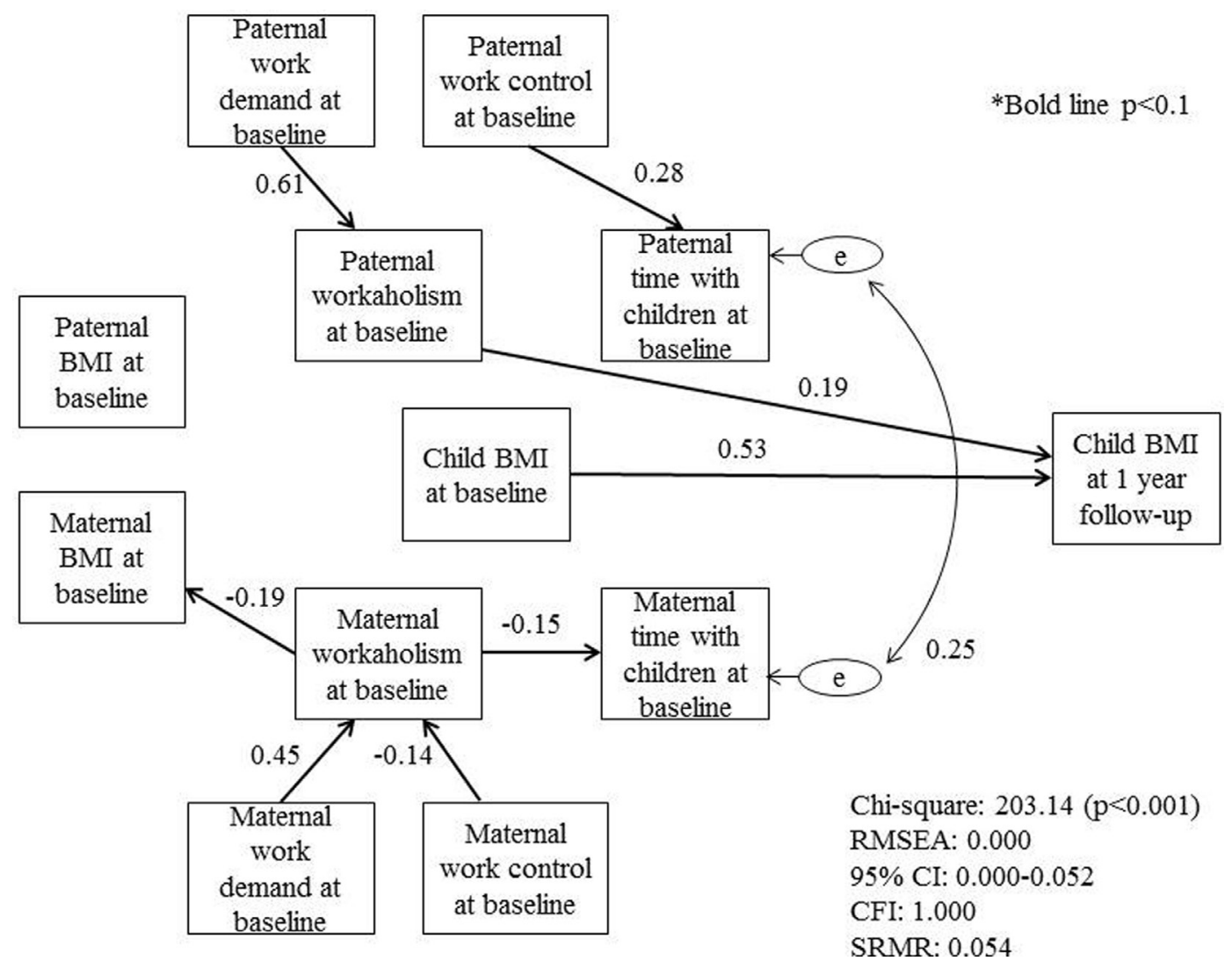

FIGURE 1 | Hypothesized model with standardized coefficients $(\boldsymbol{N}=\mathbf{1 2 5})$. Dotted line represents non-significant paths $(p>0.1)$. Chi-square $=203.14$ $(p<0.001)$, root mean square error of approximation $(\mathrm{RMSEA})=0.000,95 \%$ confidence interval $(\mathrm{Cl}) 0.000-0.052$, and comparative fit index $(\mathrm{CFI})=1.000$.

directly associated with an increase in child BMI over 1 year, regardless of paternal or maternal time spent with children or parental BMI. Our findings suggest that paternal workaholism, which was positively associated with work demands, was linked with childhood overweight or obesity 1 year after baseline.

Previous studies reported that maternal working hours were associated with childhood obesity (16-20), and few studies investigated the impact of the paternal work environment. Champion et al. revealed that non-standard paternal work schedules, defined as "shift work and working after 1800 hours (including work at home), overnight, or on weekends," showed a higher odds ratio for child overweight or obesity than did a standard working schedule after adjustment for maternal working schedules among families with 9-year-old children in Australia (21). This is consistent with the findings of the current study because workaholism is associated with working at home or work-to-family conflict (38), which was included as a non-standard work schedule, such as night-time shift working. Further, Morrissey reported that both 
maternal and paternal employment intensities are associated with higher child BMI during preschool (22). As our study focused only on dual-income families, the impact of paternal workaholism might be found only if both the mother and father are working. Nonetheless, because of the rise of women returning to work after having children, the findings suggest the importance of paternal workaholism on child BMI, which is usually not considered in the prevention of childhood obesity.

The possible mechanisms of how paternal workaholism directly increases child BMI require further research. As time spent with children did not mediate the association, the quality rather than the quantity of time spent might be more important. For example, fathers with higher scores for workaholism might be less likely to spend time engaging with their children in energetic activities, such as tag or sports, because of a high work-to-family conflict (38). Alternatively, paternal workaholism might be associated with a specific personality, which has a tendency toward a permissive or disengaged parenting style, as this parenting style leads to child overweight and obesity (25). In addition, family interaction during mealtimes, which has an association with child obesity (26), might be associated with workaholism. Further study is needed to investigate the association between paternal workaholism and the quality of time spent with children, parenting style, or paternal interaction with children during mealtimes to elucidate the relationship between paternal workaholism and child BMI.

The lack of association between maternal workaholism and child BMI might be surprising, considering the previous studies that reported maternal working hours were associated with childhood obesity (16-20). Possibly, maternal working may not be associated with the poor quality of parenting, such as providing unhealthy food that might induce obesity of children (39), because of social pressure embedded in Japanese culture. Generally, mothers are expected to be the main caretaker of her child regardless of her working status. This trend is reflected by the high rate of maternity leave $(83.4 \%)$ and low rate of paternity leave $(2.8 \%)$ in 2010 (40). As the current study is the first to report on the null association between maternal workaholism and child BMI, further replication of the study is needed to confirm the association.

This study has several limitations. First, the sample size of this study was small; more studies with larger sample sizes are needed to validate our findings. Second, although we tried to capture a population-based sample, the participants may not be a representative sample, given the relatively low response and follow-up rate. Third, as parents reported their child's weight and height, measurement error might exist, even if parental reports of child height or weight have been shown to be accurate $(33,34)$.

Based on our findings, we suggest engaging employers of fathers for reducing work demands and increasing work control through

\section{REFERENCES}

1. Ebbeling CB, Pawlak DB, Ludwig DS. Childhood obesity: public-health crisis, common sense cure. Lancet (2002) 360:473-82. doi:10.1016/ S0140-6736(02)09678-2

2. Wang Y, Lobstein T. Worldwide trends in childhood overweight and obesity. Int J Pediatr Obes (2006) 1:11-25. doi:10.1080/17477160600586747

3. Deckelbaum RJ, Williams CL. Childhood obesity: the health issue. Obes Res (2001) 9(Suppl 4):239S-43S. doi:10.1038/oby.2001.125 workplace education. As shown in Figure 1, work demands were associated with workaholism. Reducing paternal work demands might be necessary to reduce paternal workaholism, which in turn could decrease child BMI if the mother is also working. On the contrary, although paternal work control was associated with paternal time spent with children, increasing work control to prevent child obesity may not be effective because time spent with children was not associated with child BMI. In a systematic review of prevention programs for childhood obesity, study settings were limited to school, home, primary care facilities, or the community, and no study was implemented in a workplace setting (41). Further studies in the workplace are needed to address this gap to prevent childhood obesity.

\section{CONCLUSION}

Paternal, but not maternal, workaholism was associated with an increase in child BMI after 1 year. Interventions that address paternal workaholism by reducing paternal work demands might be effective to prevent overweight in children. Further study is needed to replicate these findings using a larger sample and to elucidate the mechanisms underlying the association between paternal workaholism and child BMI.

\section{ETHICAL APPROVAL}

All procedures performed in studies, involving human participants, were in accordance with the ethical standards of the Institutional Research Committee of the University of Tokyo and with the 1964 Declaration of Helsinki and its later amendments or comparable ethical standards.

\section{AUTHOR CONTRIBUTIONS}

TF and AS conceived the study; AS, MTo, and KS collected data; TF analyzed and wrote the first draft; and AS, MTo, KS, MTa, IW, NI, and NK finalized the manuscript. All authors approved the final version of the manuscript.

\section{ACKNOWLEDGMENTS}

We thank all participants who contributed to the study. We also thank Ms. Emma L. Barber of the Department of Education for Clinical Research, National Center for Child Health and Development, for editing this manuscript. This study was supported by grants from a Grant-in-Aid for Scientific Research on Innovative Areas, the Ministry of Education, Culture, Sports, Science and Technology, KAKENHI (22300228).

4. Huang RC, Burrows S, Mori TA, Oddy WH, Beilin LJ. Lifecourse adiposity and blood pressure between birth and 17 years old. Am J Hypertens (2015) 28(8):1056-63. doi:10.1093/ajh/hpu266

5. D’Adamo E, Guardamagna O, Chiarelli F, Bartuli A, Liccardo D, Ferrari F, et al. Atherogenic dyslipidemia and cardiovascular risk factors in obese children. Int J Endocrinol (2015) 2015:912047. doi:10.1155/2015/912047

6. Huang RC, De Klerk NH, Smith A, Kendall GE, Landau LI, Mori TA, et al. Lifecourse childhood adiposity trajectories associated with adolescent insulin resistance. Diabetes Care (2011) 34:1019-25. doi:10.2337/dc10-1809 
7. Mathew JL, Narang I. Sleeping too close together: obesity and obstructive sleep apnea in childhood and adolescence. Paediatr Respir Rev (2014) 15:211-8. doi:10.1016/j.prrv.2013.09.001

8. Cindik N, Baskin E, Agras PI, Kinik ST, Turan M, Saatci U. Effect of obesity on inflammatory markers and renal functions. Acta Paediatr (2005) 94:1732-7. doi:10.1080/08035250500277101

9. Perquier F, Lasfargues A, Mesrine S, Clavel-Chapelon F, Fagherazzi G. Body-size throughout life and risk of depression in postmenopausal women: findings from the E3N cohort. Obesity (Silver Spring) (2014) 22:1926-34. doi:10.1002/oby.20799

10. Han JC, Lawlor DA, Kimm SY. Childhood obesity. Lancet (2010) 375:1737-48. doi:10.1016/S0140-6736(10)60171-7

11. Jwa SC, Fujiwara T, Kondo N. Latent protective effects of breastfeeding on late childhood overweight and obesity: a nationwide prospective study. Obesity (Silver Spring) (2014) 22:1527-37. doi:10.1002/oby.20735

12. Andersen RE, Crespo CJ, Bartlett SJ, Cheskin LJ, Pratt M. Relationship of physical activity and television watching with body weight and level of fatness among children: results from the Third National Health and Nutrition Examination Survey. JAMA (1998) 279:938-42. doi:10.1001/jama.279.12.938

13. Jimenez-Pavon D, Kelly J, Reilly JJ. Associations between objectively measured habitual physical activity and adiposity in children and adolescents: systematic review. Int J Pediatr Obes (2010) 5:3-18. doi:10.3109/17477160903067601

14. Zheng M, Rangan A, Olsen NJ, Bo Andersen L, Wedderkopp N, Kristensen P, et al. Sugar-sweetened beverages consumption in relation to changes in body fatness over 6 and 12 years among 9-year-old children: the European Youth Heart Study. Eur J Clin Nutr (2014) 68:77-83. doi:10.1038/ejcn.2013.243

15. Couch SC, Glanz K, Zhou C, Sallis JF, Saelens BE. Home food environment in relation to children's diet quality and weight status. J Acad Nutr Diet (2014) 114(1569-1579):e1561. doi:10.1016/j.jand.2014.05.015

16. Hawkins SS, Cole TJ, Law C. Maternal employment and early childhood overweight: findings from the UK Millennium Cohort Study. Int J Obes (Lond) (2008) 32:30-8. doi:10.1038/sj.ijo.0803682

17. Mindlin M, Jenkins R, Law C. Maternal employment and indicators of child health: a systematic review in pre-school children in OECD countries. JEpidemiol Community Health (2009) 63:340-50. doi:10.1136/ jech.2008.077073

18. Brown JE, Broom DH, Nicholson JM, Bittman M. Do working mothers raise couch potato kids? Maternal employment and children's lifestyle behaviours and weight in early childhood. Soc Sci Med (2010) 70:1816-24. doi:10.1016/j. socscimed.2010.01.040

19. Cawley J, Liu F. Maternal employment and childhood obesity: a search for mechanisms in time use data. Econ Hum Biol (2012) 10:352-64. doi:10.1016/j. ehb.2012.04.009

20. Mitsuhashi T, Suzuki E, Takao S, Doi H. Maternal working hours and early childhood overweight in Japan: a population-based study. J Occup Health (2012) 54:25-33. doi:10.1539/joh.11-0100-OA

21. Champion SL, Rumbold AR, Steele EJ, Giles LC, Davies MJ, Moore VM. Parental work schedules and child overweight and obesity. Int J Obes (Lond) (2012) 36:573-80. doi:10.1038/ijo.2011.252

22. Morrissey TW. Trajectories of growth in body mass index across childhood: associations with maternal and paternal employment. Soc Sci Med (2013) 95:60-8. doi:10.1016/j.socscimed.2012.05.038

23. Ziol-Guest KM, Dunifon RE, Kalil A. Parental employment and children's body weight: mothers, others, and mechanisms. Soc Sci Med (2013) 95:52-9. doi:10.1016/j.socscimed.2012.09.004

24. Schaufeli WB, Bakker AB, Van Der Heijden FMMA, Prins JT. Workaholism among medical residents: it is the combination of working excessively and working compulsively that counts. Int J Stress Manag (2009) 16:249-72. doi:10.1037/a0017537

25. Wake M, Nicholson JM, Hardy P, Smith K. Preschooler obesity and parenting styles of mothers and fathers: Australian National Population Study. Pediatrics (2007) 120:e1520-7. doi:10.1542/peds.2006-3707
26. Berge JM, Rowley S, Trofholz A, Hanson C, Rueter M, Maclehose RF, et al. Childhood obesity and interpersonal dynamics during family meals. Pediatrics (2014) 134:923-32. doi:10.1542/peds.2014-1936

27. Pinquart M. Associations of general parenting and parent-child relationship with pediatric obesity: a meta-analysis. J Pediatr Psychol (2014) 39:381-93. doi:10.1093/jpepsy/jst144

28. Biernat M, Wortman CB. Sharing of home responsibilities between professionally employed women and their husbands. J Pers Soc Psychol (1991) 60:844-60. doi:10.1037/0022-3514.60.6.844

29. Wada I. Family and home. In: Japan Child and Family Research Institute, editor. Almanac of Data on Japanese Children 2015. Tokyo: KTC Chuo Shuppan (2015). p. 67-88.

30. Shimada K, Shimazu A, Bakker AB, Demerouti E, Kawakami N. Work-family spillover among Japanese dual-earner couples: a large community-based study. J Occup Health (2010) 52:335-43. doi:10.1539/joh.L9130

31. Schaufeli WB, Shimazu A, Taris TW. Being driven to work excessively hard: the evaluation of a two-factor measure of workaholism in the Netherlands and Japan. Cross Cult Res (2009) 43:320-48. doi:10.1177/1069397109337239

32. Shimomitsu T, Yokoyama K, Ono Y, Maruta T, Tanigawa T. Development of a novel brief job stress questionnaire. In: Kato S, editor. Report of the Research Grant for the Prevention of Work-Related Diseases from the Ministry of Labour. Tokyo: Ministry of Labour (1998). p. 107-15 [in Japanese].

33. Sun Y, Sekine M, Kagamimori S. Lifestyle and overweight among Japanese adolescents: the Toyama Birth Cohort Study. J Epidemiol (2009) 19:303-10. doi:10.2188/jea.JE20080095

34. Yoshitake N, Okuda M, Sasaki S, Kunitsugu I, Hobara T. Validity of selfreported body mass index of Japanese children and adolescents. Pediatr Int (2012) 54:397-401. doi:10.1111/j.1442-200X.2011.03541.x

35. Wada K, Tamakoshi K, Tsunekawa T, Otsuka R, Zhang H, Murata C, et al. Validity of self-reported height and weight in a Japanese workplace population. Int J Obes (Lond) (2005) 29:1093-9. doi:10.1038/sj.ijo.0803012

36. World Health Organization. Physical Status, the Use and Interpretation of Anthropometry. Geneva: WHO (1995).

37. Ministry of Health, Labour and Welfare. Results of National Health and Nutrition Survey in FY 2012. National Health and Nutrition Survey (2014). Available from: http://www.mhlw.go.jp/file/04-Houdouhappyou-10904750-Kenkoukyoku-Gantaisakukenkouzoushinka/0000099296.pdf

38. Shimazu A, Demerouti E, Bakker AB, Shimada K, Kawakami N. Workaholism and well-being among Japanese dual-earner couples: a spillover-crossover perspective. Soc Sci Med (2011) 73:399-409. doi:10.1016/j. socscimed.2011.05.049

39. Cabinet Office. White Paper on the National Lifestyle (2006). Available from: http://www5.cao.go.jp/seikatsu/whitepaper/h18/01_honpen/index.html

40. Ministry of Health, Labour and Welfare. Basic Survey of Gender Equality in Employment Management, FY2014. Ministry of Health, Labour and Welfare (2016). Available from: http://www.e-stat.go.jp/SG1/estat/List. do?lid $=000001137172$

41. Wang Y, Cai L, Wu Y, Wilson RF, Weston C, Fawole O, et al. What childhood obesity prevention programmes work? A systematic review and meta-analysis. Obes Rev (2015) 16(7):547-65. doi:10.1111/obr.12277

Conflict of Interest Statement: The authors declare that the research was conducted in the absence of any commercial or financial relationships that could be construed as a potential conflict of interest.

Copyright (c) 2016 Fujiwara, Shimazu, Tokita, Shimada, Takahashi, Watai, Iwata and Kawakami. This is an open-access article distributed under the terms of the Creative Commons Attribution License (CC BY). The use, distribution or reproduction in other forums is permitted, provided the original author(s) or licensor are credited and that the original publication in this journal is cited, in accordance with accepted academic practice. No use, distribution or reproduction is permitted which does not comply with these terms. 